Paidéia, 2005, 15(32), 333-338

\title{
A ÉTICA NAS RELAÇÕES DE TRABALHO: REFLEXÕES SOBRE FONTES DE PODER EM FOUCAULT E HELLER ${ }^{1}$
}

\author{
Elisabeth Caldeira Villela \\ Patrícia de Souza Pita \\ Graziela Breitenbauch \\ Universidade do Vale do Itajaí
}

Resumo: Este trabalho ressalta a dificuldade da cultura produtiva de valorizar a identidade pessoal do sujeito além da profissional. As competências proclamadas como essenciais à sobrevivência pessoal e organizacional, tais como: autonomia, liderança, comunicação e cooperação são analisadas em Foucault e Heller, no confronto dos sujeitos, no qual construir o "eu” e o "nós” conjuga um processo educacional. Conclui-se que, a subjetividade, desde os séculos XVIII até início do século XXI encontra-se empobrecida na sua existência como "ser" e valorizada como "dever ser". Aprender a lidar com as normas exige dedicação, compromisso, responsabilidade, para aprender a optar, decidir, discernindo atitudes e exercendo o princípio da liberdade.

Palavras-chave: Identidade; trabalho; dimensão ética educativa.

\section{ETHICS IN WORK RELATIONSHIPS: REFLECTIONS ON POWER SOURCES IN FOUCAULT AND HELLER}

\begin{abstract}
This paper stands out the productive culture difficulty to value the citizen's personal identity beyond the professional one. The abilities proclaimed as essential to the personal and organizational survival, such as autonomy, leadership, communication and cooperation are analyzed, in Foucault and Heller, in the confrontation of the citizens, in which to construct "me" and "us" promotes an educational process. It is concluded that the subjectivity, since the $18^{\text {th }}$ until the beginning of the $21^{\text {st }}$ century, is found poor in its "to be" existence and valued as "ought to be". Learning to deal with the norms demands devotion, commitment and responsibility to learn, choose and decide, discerning attitudes and exerting the principle of freedom.
\end{abstract}

Key words: Identity; work; dimension ethics educative.

Introdução: As ofertas de empregos, as formas de trabalho e o perfil do profissional estão, no momento, redefinidos em escala mundial pela modernização tecnológica e gerencial e pelo ordenamento econômico. São exigências e transformações impostas no mundo do trabalho e na educação que prevê a articulação da identidade consolidada na formação do sujeito à identidade solicitada nas relações de trabalho, como desafio humano de empregabilidade. $\mathrm{O}$ sujeito constituído na relação social marcada, até então pela estabilidade e dependência, sofre uma desestrutura-ção brutal com o estável, que se tornou

\footnotetext{
Artigo recebido em 20/09/2005, aceito para publicação em 20/02/2006. ${ }^{2}$ Endereço para correspondência: Elisabeth Caldeira Villela, Rua Uruguai, 458, sala 106, bloco 07 - Itajaí-SC, CEP: 88302-202, Email: caldeira@univali.br
}

ameaçante e ainda com o instável, que se tornou valorizante.

Neste sentido, Foucault e Heller denunciam que um saber econômico se acumulou desde o fim da Idade Média, difundindo-se igualmente pelos domínios de exercício de poder referente ao saber e ao conhecimento. É preciso que a subjetividade seja fortalecida no mundo do trabalho, minimizando formas de dominação e desigualdade de oportunidades, para se conceber como produtor da vida organizacional e de suas mudanças.

Conceitos como auto-organização, descentralização, liderança, autonomia, participação, cooperação, moral e outros princípios democráticos, ilustram os discursos, sejam estes educacionais, gerenciais ou 


\section{Elisabeth Caldeira Villela}

políticos. Contudo, estes conceitos oportunizam entender a extraordinária complexidade das organizações modernas, do comportamento humano e das práticas gerenciais.

\section{O Poder nas Relações de Trabalho}

A utopia da fábrica prisão foi realmente consolidada. Conforme Foucault (1979), são duas as espécies de utopia: as proletárias socialistas que possuem a característica de nunca se realizarem e as capitalistas que o fazem constantemente, por uma série de instituições do tipo: pedagógico - escolas, orfanatos, centros de formação; correcionais - casa de recuperação e correção; e ainda, as terapêuticas - hospitais, asilos, que se espalharam por toda a sociedade ocidental.

Porém, estas instituições se manifestaram inviáveis do ponto de vista capitalista e governamental. Com carga econômica pesada e estrutura rígida, têm a tendência de desaparecerem ou sobreviverem precariamente, apesar de sua finalidade ser a não exclusão, mas a integração do indivíduo à estrutura institucional.

No setor industrial, ele se encontra ligado a um aparelho de produção. Na escola, a um de transmissão e produção de conhecimento. Em casas de tratamento, a um de normalização, de correção ou de internamento - prisão. Enfim, "trata-se de garantir a produção ou os produtores em função de uma determinada norma”.(Foucault, 1973, p. 92). Nesta concepção, o poder pode ser necessário para dar sustentação à autoridade, que diz respeito a uma ordem normativa que regula o comportamento social por aceitação dos que se submetem ao sistema dela.

Porém, existe uma oposição à sociedade feudal pela moderna. Na feudal e em muitas primitivas, os indivíduos eram controlados a partir da inserção local, ou seja, pelo lugar e espaço ao qual pertenciam. Afirma Foucault (1973, p. 93), “a inscrição geográfica local é um meio de exercício do poder”. A sociedade moderna, com sua formação no início do século XIX, apresenta-se indiferente à pertinência espacial dos indivíduos. O controle espacial já permanece garantido desde a feudal, independente do local. O tempo das pessoas - de vida e existência passa a ser utilizado como aparelho de produção e a se constituir tempo de trabalho. Ocorre que as extra- ções do tempo, associadas às necessidades de controlar as economias dos trabalhadores, passam pelo controle de instituições, como caixas econômicas e de assistência, a partir da década de 1820, especialmente, anos 40 e 50, cuja finalidade era de não existir gasto antes do desemprego.

Todo esse controle geográfico, temporal e econômico sobre os indivíduos, completa-se com o seqüestro de seus corpos. As instituições feitas para produzir (fábricas), para curar (hospitais), para ensinar (escolas) e para punir (prisões) tinham uma grande preocupação com a sexualidade. O controle social do corpo até o século XVIII, supliciado e castigado, adquire nova significação a partir do século XIX: ele necessita ser corrigido, reformado, enfim, qualificar-se para se tornar capaz de trabalhar, sendo em todas as instituições, construído um poder não somente econômico, mas também político, judiciário e epistemológico. do seqüestro:

Foucault (1973) define-as como instituições

“[...] através destes jogos do poder e saber, poder múltiplo e saber que interfere e se exerce simultaneamente nestas instituições, temos a transformação da força do tempo e da força de trabalho e sua integração na produção. Que o tempo da vida se torne tempo de trabalho, que o tempo de trabalho se torne força de trabalho, que a força de trabalho se torne força produtiva; tudo isto é possível pelo jogo de uma série de instituições que esquematicamente, globalmente, as define como instituições do seqüestro.” (p.98)

Neste sentido o poder proíbe, oprime, de forma muitas vezes irracional, podendo envolver coerção física ou psicológica. É exercido sempre de cima para baixo, de maneira vertical, repreendendo os interesses daqueles que são sujeitos. Na educação ele normalmente é usado como um incômodo, ou melhor, um mal necessário, vindo da autoridade daqueles que se apropriaram do poder.

A linguagem, a análise e a prática política estão imersas numa narrativa que inclui coisas como: opressão, legitimação, direitos, Estado, governo e autoridade. Foucault acredita que somos capazes de efetuar escolhas livres e autônomas, numa construção que permite ser governado, tanto individual como coletivamente. O papel do Estado deve ser mínimo, 


\section{A Ética nas relações de trabalho 335}

com liberdade e direito das pessoas escolherem seu próprio projeto.

$$
\text { Foucault (1982) declara: }
$$

O poder só se exerce sobre 'sujeitos livres', enquanto 'livres' - entendendo-se por isso sujeitos individuais ou coletivos que têm diante de si um campo de possibilidade onde diversas condutas, diversas reações e diversos modos de comportamentos podem acontecer (p.244).

Os confrontos podem ser evitados, tendo em vista que empregados e empregadores são ditos parceiros na perseguição de objetivos e metas, quando a relação de poder se desenrola sob a perspectiva da colaboração, da participação e da parceria.

Assim, o homem produz sua existência por meio do trabalho, desenvolvendo relações econômicas e sociais. Em pleno século XX e início do XXI é vivenciado o confronto com o mercado de trabalho, permeado de incertezas e de concorrência. O indivíduo que trabalha, o faz de acordo com valores e princípios da cultura organizacional, sendo observado e valorizado pelos resultados que seu trabalho traz à organização. Os valores compartilhados a partir da linguagem levam a cultura organizacional a estruturar a ação dele, direcionando suas atitudes e controlando a sua forma de atuação.

Na medida em que o trabalho implica um exercício de si mesmo, o ser é requisitado a investir no seu contínuo aprendizado, colocando-se como agente de sua própria evolução. Chega-se à ética como exercício de si mesmo, a um desafio ao fenômeno de dominação.

O ser humano vive um momento crucial de identidade profissional, que constitui também uma projeção de si no futuro, por sua trajetória de empregabilidade, aspirações de reconhecimento e sobrevivência num contexto de acesso desigual, complexo e instável.

A formação pessoal e profissional se constitui em um componente cada vez mais valorizado, não somente de acesso, mas de manutenção e valorização do indivíduo no trabalho. Para Foucault (1994), a atribuição de valor à ética pode ser entendida como desdobramento da politização da noção de identidade, em meio às fronteiras frágeis na contemporaneidade entre o pessoal, o privado e o público. Por suas competências, a identidade do sujeito requer a articulação entre a construção da identidade para si e para outrem.

Ocupar-se de si - o que de uma forma ou de outra
está presente em toda ética desde a falência da
ética coesiva - não é uma preparação para a vida;
é uma forma de vida. (...) Não há outro fim nem
outro termo além do propósito de estabelecer-se
junto a si, 'residir em si mesmo', fazer aí sua mora-
da". (p. 356).

Neste sentido, a construção do eu solicita o investimento da personalidade em aprender a lidar com as normas sociais, políticas ou morais. Caso contrário, com a liberação total delas, o indivíduo tornase não-livre pela decomposição do próprio eu. Aprender a lidar com elas é um trabalho também realizado com renúncia e amadurecimento, para poder optar, decidir, discernir atitudes e exercer o princípio da liberdade, o próprio eu. Segundo Heller (1998), “o eu é a única rocha onde as forças do poder podem se partir.” (p. 409).

A dimensão ética implica fundamentalmente em relações reflexivas de si para consigo. Neste sentido, Foucault (1994) levanta a questão: “como nós constituímos nossa identidade por meio de certas técnicas éticas de si que se desenvolveram desde a antiguidade até nossos dias?” (p. 814).

Pode-se refletir sobre o motivo pelo qual o homem moderno constitui critérios de subjetividade na busca de espaço e liberdade. O que se observa, atualmente, é a proclamação do papel de líder nas instituições, como líder inovador, a fim de que as pessoas encontrem significado naquilo que fazem, na busca da "ética do prazer".

A "ética do prazer", neste sentido, deveria substituir à "ética do dever”, permitindo que o indivíduo além de seu processo de produção possa investir no de aprendizagem e formação pessoal, conforme Diagrama 1, a seguir: 
Diagrama 1 - Na busca da ética do prazer

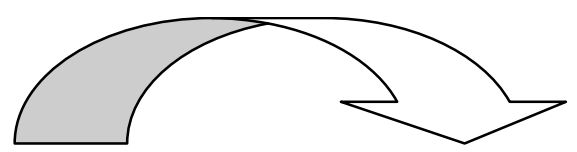

- Informação: Fonte de poder

- Comunicação Unidirecional, Ruidosa e Distorcida

- Campo de Disputa entre chefias

- Relações de Desentendimentos e Amargura

- Decisões baseadas no achismo

- Dependência

- Imposição

- Berço da omissão e do conflito camuflado
- Informação: Fonte de ação

- Legitimidade

- Produtividade

- Profissionalismo - Investimento

- Programas de Educação - Formação para a Vida:

- Conceitos, Atitudes e Valores

- Contínua busca do Auto Desenvolvimento

- Cidadania/Humanização

- Promoção da Crítica
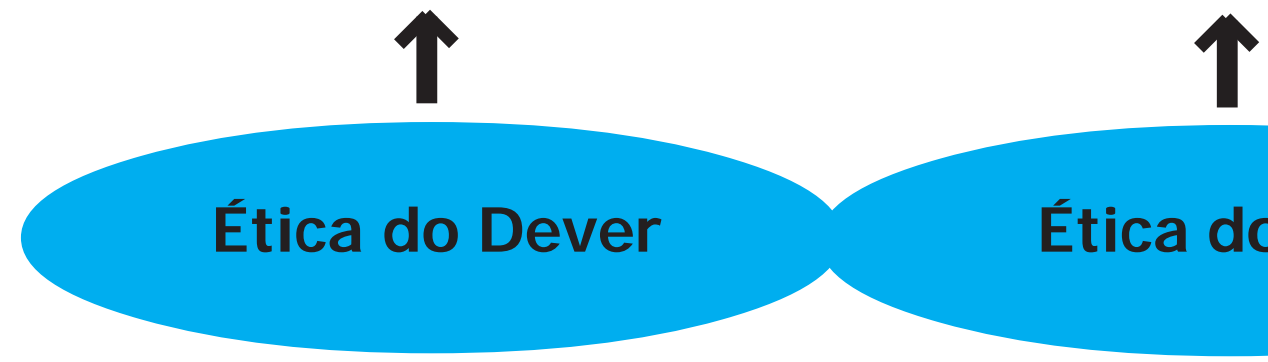

\section{Ética do Dever \\ Ética do Praser}

Para tanto, compete à educação seu redimensionamento social, para além do conhecimento científico-tecnológico, contemplando as dimensões humana e ética nos espaços educativos para dar conta da vida em sociedade, minimizando a exclusão e oportunizando o processo de mudança, sendo necessário um novo padrão atitudinal que redimensione o lugar privilegiado dela nos processos de reestruturação produtiva, superando o educar voltado exclusivamente para o mercado, no contexto da globalização.

Para corresponder às novas exigências da produtividade, o sujeito se vê muitas vezes pressionado a superar a si mesmo. A dimensão subjetiva, geralmente, encontra seu paradeiro e identificação no cargo, distante de sua identidade pessoal e das relações com os outros.

Para minimizar tal situação, propõe-se, no Diagrama 2, a superação do “dever ser” para a integração subjetiva do "ser-fazer-conhecer e conviver".

\section{Diagrama 2: Existência do Ser}

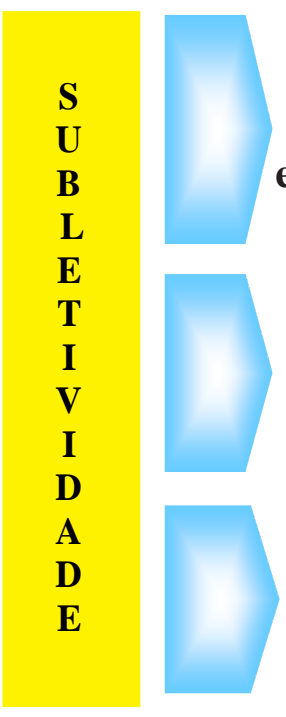

Encontra-se empobrecida na sua existência como "ser" e valorizada como "dever ser".

É preciso que a formação pessoal seja contemplada na profissional.

\section{Feliz integração do} ser-fazer-conhecer-conviver. 
Atualmente nos modelos de organização empresarial e profissional, encontra-se dupla fonte de poder e legitimidade: os dirigentes da empresa representados pelo capital e os profissionais e assalariados excluídos da sua acumulação; são duas fontes de poder e de relações de trabalho e capital. A primeira, objetiva reduzir o custo e garantir a sobrevivência da empresa. Quanto à segunda, cabe-lhe negociar as condições, a remuneração e a valorização de sua força de trabalho. Portanto, são fontes de poder divergentes e antagônicas.

O desafio está na articulação e negociação destas duas forças, pois não se garante a sobrevivência de ambas e o alcance de resultados positivos sem o empenho delas. Segundo Heller (1998)

" a construção da personalidade não é uma jornada de prazer, mas uma espécie de trabalho, e um trabalho que envolve algum sofrimento, o nosso próprio eu é a nossa liberdade." (p.409).

A formação pessoal e profissional dos dirigentes educacionais e empresariais, em sua maioria, baseia-se em uma filosofia organizativa que acentua a divisão social e técnica do trabalho; assim, encontram-se despreparados para agir com consciência democrática e espírito colaborativo, pois uns são educados para pensar e decidir, outros o são para obedecer e fazer.

Uma grande questão deve preocupar a educação: Como promover a construção do sujeito com consciência democrática para ser autor de sua biografia pessoal e profissional, sem ser excluído do processo de produção capitalista? Considera-se este um dos grandes desafios da educação na sociedade contemporânea e globalizada. Segundo Foucault (1995) "temos que criar à nós mesmos como uma obra de arte”. (p. 262).

Há forte influência do mecanismo newtoniano e do dualismo de Descartes. Muitos gestores empresariais e educacionais têm incorporado, em seu psiquismo, atitudes compatíveis com um sistema fechado, sem desafios, perturbações e possibilidades de reorganizar criativamente suas ações.

As inovações, de certa forma, assustam mesmo as pessoas que desejam inovar. A conservação de atitudes geradas, principalmente pela educação skinneriana, dificulta a formação do profissional com- patível com um sistema aberto, propício à alteração. O modelo atual de mudança é o da emergência e crescimento, possibilitado pela dialética, transação, diálogo, consenso, desequilíbrio e equilíbrio.

Assim, uma lógica de aprendizagem, em formação continuada, constitui-se num processo contínuo e dialético. Para Foucault (1979), a dialética é uma maneira de evitar a realidade com seu caráter violento, reduzindo-o à forma calma do entendimento e diálogo. $\mathrm{O}$ autor afirma que:

A dialética é uma maneira de evitar a realidade aleatória e aberta desta inteligibilidade reduzindo ao esqueleto hegeliano; e a "semiologia" é uma maneira se evitar seu caráter violento, sangrento e moral, reduzindo-a a forma apaziguada e platônica da linguagem e do diálogo.(p. 5).

Um sistema aberto e orgânico tem a natureza transformativa, pois a mudança é sua essência, utilizando desafios e perturbações para se reorganizar criativamente. O movimento dialético pede que os profissionais criem relações capazes de providenciar mecanismos saudáveis de reestruturações. Caso contrário, as ações humanas permanecem no nível de proposições intuitivas, do imediato, sem condições de analisar e enfrentar desafios provenientes de uma conjuntura econômica e política mais ampla.

O que geralmente se vivenciam nas relações de trabalho Foucault já criticou há muito tempo; são momentos de indefinição e incertezas que incentivam à competição e a indeterminação do futuro eliminando a cooperação. O conservadorismo, o clientelismo e a ineficiência dificultam o progresso e o desenvolvimento social. As atitudes individualistas precisam ser revisadas ou abandonadas, superando formas consagradas de agir repressivo.

Neste confronto com o mercado de trabalho, se situa um desafio subjetivo e empresarial. Neste afrontamento, as organizações proclamam o resgate do sujeito capacitado para tal e se prontificam a habilitá-lo, com estratégias pessoais de apresentação de si, ou seja, o sujeito deve aprender a lidar com a imagem do eu e a apreciação de suas capacidades.

O desencadear de uma nova lógica de aprendizagem se legitima nas esferas do trabalho e na educação continuada, como acesso e permanência no mundo do trabalho. 


\section{Elisabeth Caldeira Villela}

\section{Considerações finais}

Proclama-se o sujeito autônomo para agilizar o processo social inovador. A dimensão ética educativa enaltecida pelos programas organizacionais e educacionais é ainda carente de princípios subjetivos, mais identificada com aspectos objetivos, ou seja, com produtividade e qualidade. Pode-se afirmar que, a subjetividade ainda se encontra empobrecida na sua existência como "ser" e valorizada como “dever ser”; é preciso que a formação pessoal seja contemplada na profissional, numa integração do ser-fazer-conhecerconviver.

O incentivo à capacidade criativa e crítica é uma tentativa de qualificar o indivíduo nas relações de trabalho. Prega-se a cooperação, embora ainda não efetivada no enfrentamento com as limitações individuais e institucionais para implantá-la.

Aprender a lidar com as normas é um trabalho educacional que exige dedicação, compromisso, responsabilidade, pois cada pessoa tem que aprender a optar, decidir, discernindo atitudes e exercendo o princípio da liberdade, o próprio eu, rachando as forças alienantes do poder.

Finalmente, pode-se concordar com Foucault e Heller, em que a construção do eu supõe a escolha de princípios e valores, no enfrentamento contínuo com regras funcionalistas, efetivando a escolha existencial, que é sempre relativamente autônoma, pois guiada por uma matriz social, seja repressiva ou dialógica.

\section{Referências Bibliográficas}

Foucault, M. (1973). A verdade e as formas jurídicas. La vérité et lês formes juridiques. Conferências de Michel Foucault na PUC. Rio de Janeiro.

Foucault, M. (1979). Microfísica do poder. Rio de Janeiro: Edições Graal.

Foucault, M. (1982). Vigiar e punir: uma história das prisões. Petrópolis: Vozes.

Foucault, M. (1994). Dits et écrits. Paris: Gallimard.

Foucault, M. (1995). Sobre a genealogia da ética: uma revisão do trabalho. Em Rabinow, Paul; Dreyfus, Hubert, Michel Foucault. Uma trajetória filosófica: para além do estruturalismo e da hermenêutica. Rio de Janeiro: Forense Universitária.

Heller, A. (1998). Além da justiça. Rio de Janeiro: Civilização Brasileira. 